\title{
A Guide to the Calculation of Theoretical Densities of Crystal Structures for Solid Oxide Fuel Cells
}

\section{Rachel Rosten, Matt Koski and Eric Koppana}

\author{
Michigan Technological University, Department of Materials Science and Engineering \\ Houghton, Michigan 49931
}

Abstract

Theoretical density is an important parameter used to estimate the porosity of materials after sintering, especially if the requirements for the materials' densities are strict, such as in the case of the parts of solid oxide fuel cells. In this research paper, we provide examples of theoretical density calculations using unit cell structure and X-ray diffraction determined lattice parameters for a number of different ceramics, which are important for energy applications. Oxide perovskites, fluorites and rock salts were all investigated.

Keywords: Solid oxide fuel cells, lattice parameter, perovskite, fluorite

\section{Introduction}

The need for alternate forms of energy is apparent with increasing oil prices and growing concern over the limited supply of fossil fuels. Research addressing alternative energy sources continues to increase, especially in the area of fuel cells. One type of fuel cell receiving considerable attention is the solid oxide fuel cell (SOFC). Like other fuel cells, SOFCs release no polluting emissions, their only byproduct being water, and they are also much more efficient than current methods of electricity production. ${ }^{[1]}$

Solid oxide fuel cells are composed of an anode, a cathode, and an electrolyte sandwiched between them, all three of which are made from ceramics. As displayed in Figure 1, when the fuel cell is operating, oxygen molecules from air are doubly ionized on the cathode side of the fuel cell. These ions then pass through the oxygen permeable electrolyte to the anode. ${ }^{[2]}$ The cathode is commonly composed of perovskite materials, such as Sr- or Ca-doped $\mathrm{LaMnO}_{3}$, while the electrolyte is often composed of Yttria-stabilized zirconia. ${ }^{[3]}$ On the anode side of the SOFC, hydrogen molecules are positively ionized and combine with the oxygen ions that have diffused through the electrolyte, forming water as a byproduct. Anode materials are typically composed of Ni/Yttria-stabilized zirconia. ${ }^{[3]}$ The electrons released by the ionized hydrogen create a current that can be used to provide power to external devices as they return to the cathode where they are used to ionize more oxygen. In this way, the process continuously provides a constant supply of oxygen and hydrogen to the fuel cell.
The theoretical density of the materials of the anode, cathode, and electrolyte are used to calculate the porosity of the materials, a critical parameter in determining if the fuel cell will function properly. The anode and cathode must both have a reasonably high porosity (about 30\%) to allow gas to diffuse through them to the electrolyte. On the other hand, the electrolyte must be fully dense to prevent the diffusion of air through it, because only oxygen ions and electrons must be allowed to diffuse between the anode and cathode if the SOFC is to function properly. These theoretical densities are calculated from the relative proportions of the atoms present in the material, as indicated by the chemical formula, their atomic masses, the known chemical structure, and the lattice parameters of the unit cell. The lattice parameters of a material were determined from X-ray diffraction (XRD) patterns of the compounds of interest presented in Figure 2. A Scintag XDS 2000 diffractometer was used to collect the diffraction patters from a $2 \theta$ range of $20-80^{\circ}$ with a step size of $0.03^{\circ}$ and a collection time of $12 \mathrm{~s}$.

Though the procedure for calculating the theoretical density is rather straightforward, several papers

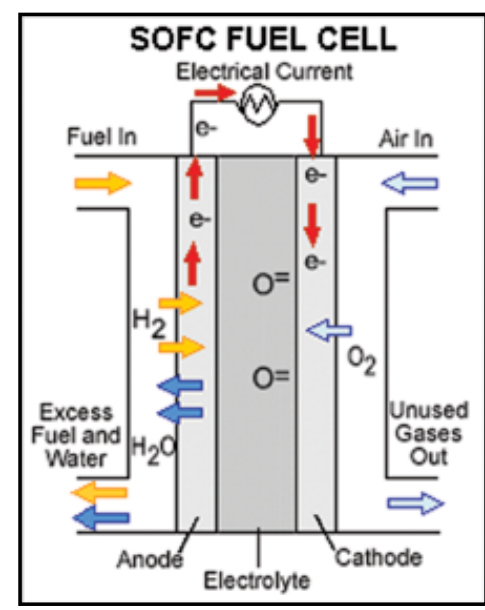

Figure 1. Schematic presentation of solid oxide fuel cell. ${ }^{[2]}$ 
have incorrect or conflicting values for different compounds. The methodology can also be somewhat more complicated for researchers lacking a background in chemistry or materials science and engineering. For this reason, this guide has been written. While the materials of focus in this paper are those of interest for SOFCs, the same methodology can be applied to calculate the theoretical density of almost any compound.

\section{Ceramic Oxide Crystal Structures}

\subsection{Perovskite Structure}

Perovskites are materials with a chemical formula of $\mathrm{ABO}_{3}$. The basic crystal structure is cubic, with one A cation at the center and a B cation at each corner of the cube. The oxygen anions are located at the center of each cube edge as shown in Figure 3. Materials used in SOFCs typically have substitutions of some of the atoms at the A site, the B site, or both. For example, if the $\mathrm{A}$ site is a $\mathrm{La}$ ion, $5 \%$ of these ions may be replaced by $\mathrm{Sr}^{2+}$ ions. In addition, there can be deficiencies at some of the sites, meaning that some of the sites are vacant and the ratio of the elements present is not exactly 1:1:3. Furthermore, many perovskites have distorted unit cells, that is, rather than being cubic, they may be rhombohedral or orthorhombic.

\subsection{Fluorite Structure}

Another material type of interest in SOFCs is the fluorite structure, which has a chemical formula of $\mathrm{AO}_{2}$. The crystal structure shown in Figure 4 consists of cubes with $\mathrm{B}$ anions at each corner and A cations at the center of every other cube. A

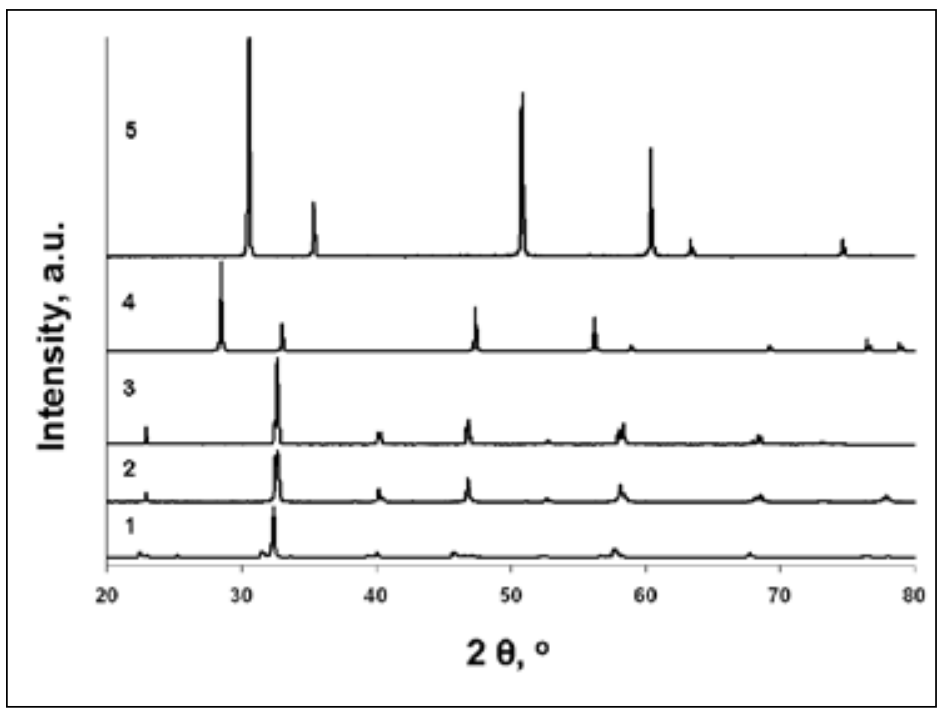

Figure 2. XRD scans of perovskite and fluorite structures used for calculating lattice parameters 1) $\mathrm{LaMnO}_{3}$;

2) $\mathrm{La}_{0.6} \mathrm{Sr}_{0.4} \mathrm{Fe}_{0.8} \mathrm{Co}_{0.2} \mathrm{O}_{3 ;}$ 3) $\left(\mathrm{La}_{0.9} \mathrm{Sr}_{0.1}\right)_{0.95} \mathrm{Cr}_{0.85} \mathrm{Mg}_{0.1} \mathrm{Ni}_{0.05} \mathrm{O}_{3}$;

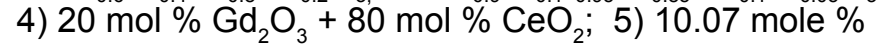

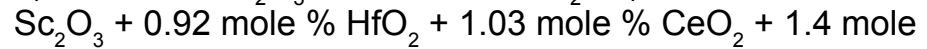
$\% \mathrm{TiO}_{2}+86.58$ mole $\% \mathrm{ZrO}_{2}$ unit cell contains four sets of cube pairs, with each pair containing one cube with an A cation and one without. Another way of considering the structure is as an FCC arrangement lattice of anions with the cations occupying the tetrahedral sites, leaving the octahedral sites unoccupied. As with the perovskites, substitutions and deficiencies are often used in fluorites of interest to SOFCs.

\subsection{Rock Salt Structure}

A third structure considered is rock salt, which has a chemical formula of $\mathrm{AO}$. The $\mathrm{A}$ and $\mathrm{O}$ ions are located at the corners of simple cubes, with adjacent cubes formed as mirror images of one another as displayed in Figure 5. In other words, the A and $\mathrm{B}$ ions alternate in their location in the lattice. As is the case with the fluorites, it takes four cube pairs to form a unit cell.

\section{Theoretical Density Calculation}

\subsection{Examples of Calculations of Perouskites}

a) $\left(\mathrm{La}_{0.9} \mathrm{Sr}_{0.1}\right)_{0.95} \mathrm{Cr}_{0.85} \mathrm{Mg}_{0.1} \mathrm{Ni}_{0.05} \mathrm{O}_{3}$ (LSCMN)

The chemical formula of the perovskite $\left(\mathrm{La}_{0.9} \mathrm{Sr}_{0.1}\right)_{0.95} \mathrm{Cr}_{0.85} \mathrm{M}$ $\mathrm{g}_{0,1} \mathrm{Ni}_{0.05} \mathrm{O}_{3}$ indicates that the basic structure of the material is $\mathrm{LaCrO}_{3}$, where $\mathrm{A}=\mathrm{La}$ and $\mathrm{B}=\mathrm{Cr}$, but $10 \%$ of the La atoms

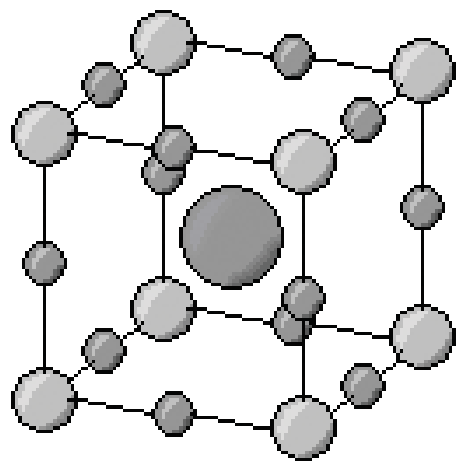

Figure 3. A schematic presentation of perovskite structure

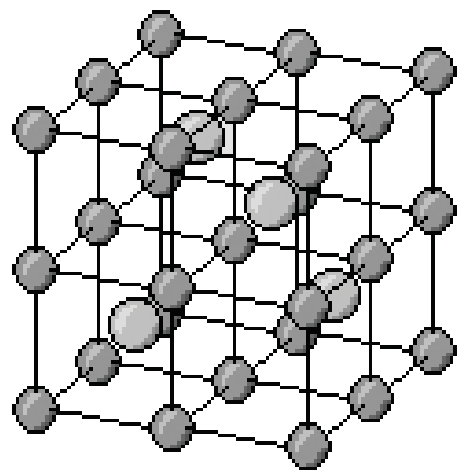

Figure 4. A schematic presentation of fluorite structure are substituted by $\mathrm{Sr}$ atoms, $10 \%$ of the $\mathrm{Cr}$ atoms are substituted by $\mathrm{Mg}$ atoms, and $5 \%$ of the $\mathrm{Cr}$ atoms are substituted by $\mathrm{Ni}$ atoms. In addition, $5 \%$ of the unit cells will have neither a $\mathrm{La}$ atom nor a $\mathrm{Sr}$ atom; that is, there is a $5 \%$ deficiency at the perovskite A site. It is necessary to calculate the average mass of a unit cell, but first the formula mass is calculated using the masses

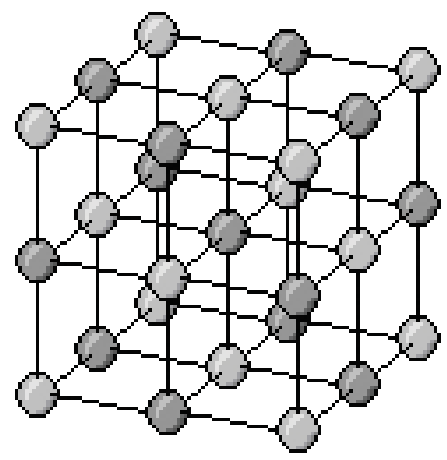

Figure 5. A schematic presentation of rock salt structure 
referenced in Table 1 and the subscripts of the chemical formula.

From the chemical formula, $90 \%$ of $95 \%$ of A sites, or $85.5 \%$ of sites, contain and La ion and similarly $9.5 \%$ are occupied by a Sr ion, and 5\% contain no ion at the perovskite A site; thus, the average mass of the A site will be

$0.855 * 138.91+0.095 * 87.62+0.05 * 0=127.0920 \mathrm{amu}$

Using the same principles for the $\mathrm{B}$ site and $\mathrm{O}$ ions, the total formula mass is

$0.855 * 138.91+0.095 * 87.62+0.85 * 51.996+0.1 * 24.312+$

$0.05 * 58.71+3 * 15.999=224.652 \mathrm{amu}$

Since $1 \mathrm{amu}=1.6605^{*} 10^{-24} \mathrm{~g}$, the formula mass is then $3.7304 * 10^{-22}$ grams.

The unit cells of this structure are orthorhombically distorted. From XRD analysis, $\mathrm{a}=5.46 \AA \mathrm{,b}=7.75 \AA$, and $\mathrm{c}=5.51 \AA$, so the volume of the orthorhombic unit crystal is simply $a^{*} b^{*} c$, which equals $233.15 \AA^{3}$, or $233.15^{*} 10^{-24} \mathrm{~cm}^{3}$.

Density is simply mass divided by volume. Because of the orthorhombic structure, there are four formula units in each unit cell, which requires the formula mass to be multiplied by four in calculating the theoretical density. The density is then

$\rho_{\text {LSCMN }}=$

$\left(4 * 3.7304 * 10^{-22} \mathrm{~g}\right) /\left(233.15 * 10^{-24} \mathrm{~cm}^{3}\right)=6.40 \mathrm{~g} / \mathrm{cm}^{3}$

b) $\mathrm{LaMnO}_{3}(\mathrm{LM})$

$\mathrm{LaMnO}_{3}$ is another perovskite with orthorhombic distortion; therefire, the formula mass must again be multiplied by four to calculate the proper density. There are no substitutions of the ions at the A or B sites for this material, so we simply add the atomic masses of $\mathrm{La}, \mathrm{Mn}$, and three times $\mathrm{O}$ to determine a formula mass of $241.857 \mathrm{amu}, 4.016^{*} 10^{-22} \mathrm{~g}$. Lattice parameters from XRD analysis are $\mathrm{a}=5.70 \AA, \mathrm{b}=7.72 \AA$, and $\mathrm{c}=$ $5.54 \AA$. Using these parameters, the volume of the unit cell is $2.4378 * 10^{-22} \mathrm{~cm}^{3}$. The density is then,

$\rho_{\mathrm{LM}}=\left(4 * 4.016 * 10^{-22} \mathrm{~g}\right) /\left(2.44 * 10^{-22} \mathrm{~cm}^{3}\right)=6.59 \mathrm{~g} / \mathrm{cm}^{3}$

c) $\mathrm{La}_{0.6} \mathrm{Sr}_{0.4} \mathrm{Fe}_{0.8} \mathrm{Co}_{0.2} \mathrm{O}_{3}$ (LSFC)

An example of a perovskite with rhombohedral distortion is $\mathrm{La}_{0.6} \mathrm{Sr}_{0.4} \mathrm{Fe}_{0.8} \mathrm{Co}_{0.2} \mathrm{O}_{3}$. However, the lattice parameters and volume determined for the unit cell are for a hexagonally shaped unit cell. There are two formula units in a rhombohedra, and

Table 1. Atomic masses for all discussed materials

\begin{tabular}{|c|c|c|c|c|c|c|c|c|}
\hline Element & $\mathrm{Ce}$ & $\mathrm{Co}_{0}$ & $\mathrm{Cr}$ & $\mathrm{Fe}$ & Gd & HE & $\mathrm{La}$ & $\mathrm{Mg}$ \\
\hline 2ase (amu) & 140.12 & 58.933 & 51.996 & 55.847 & 157.25 & 178.49 & 138.91 & 24.312 \\
\hline Element & $\mathrm{Mn}$ & $\mathrm{N}_{1}$ & 0 & Sc & St & II & $2 t$ & \\
\hline Mass (amu) & 54.95 & 58.71 & 15.999 & 44.956 & 87,62 & 47.9 & 91.22 & \\
\hline
\end{tabular}

$40 \cdot J U M R$ three rhombohedra to a hexagonal unit cell. As a result, the formula mass must be multiplied by six to calculate the proper mass of the unit cell. So while the formula mass is then 222.855 amu, or $3.7006 * 10^{-22}$ grams, the average mass of the unit cells is $2.2204 * 10^{-21}$ grams. The volume is more difficult to calculate from the lattice parameters, because the angles of the unit cell are not right angles, but the XRD software can also calculate volume and in this case determined the volume to be $3.49 \times 10^{-22}$ $\mathrm{cm}^{3}$. Thus the calculated theoretical density for this material is

$\rho_{\mathrm{LSFC}}=\left(2.2204 * 20^{-21} \mathrm{~g}\right) /\left(3.49 * 10^{-22} \mathrm{~cm}^{3}\right)=6.36 \mathrm{~g} / \mathrm{cm}^{3}$

\subsection{Examples of Calculations of Fluorite}

a) 10.07 mole $\% \mathrm{Sc}_{2} \mathrm{O}_{3}+0.92$ mole $\% \mathrm{HfO}_{2}+1.03$ mole $\%$ $\mathrm{CeO}_{2}+1.4$ mole $\% \mathrm{TiO}_{2}+86.58$ mole $\% \mathrm{ZrO}_{2}$

There is a solid solution of $\mathrm{Sc}_{2} \mathrm{O}_{3}, \mathrm{HfO}_{2}, \mathrm{CeO}_{2}$, and $\mathrm{TiO}_{2}$ in the $\mathrm{ZrO}_{2}$ lattice. The calculation of the density of this solid solution is more difficult than the previous calculations because the chemical formula must be determined before the formula mass can be calculated. $\mathrm{ZrO}_{2}$, which forms the matrix of this solid solution, is a fluorite, so final formula should be of the form $\mathrm{AO}_{2}$, though the ratio will not be exactly 1:2. This is because of the 3:2 anion to cation ratio for $\mathrm{Sc}_{2} \mathrm{O}_{3}$, as opposed to the 2:1 ratio for the other oxides, which results in an oxygen deficiency. One mole of the solution is made from $10.07 \mathrm{~mol} \%$ $\mathrm{Sc}_{2} \mathrm{O}_{3}, 0.92 \mathrm{~mol} \% \mathrm{HfO}_{2}, 1.03 \mathrm{~mol} \% \mathrm{CeO}_{2}, 1.4 \mathrm{~mol}^{\%} \mathrm{TiO}_{2}$, and $86.58 \mathrm{~mol} \% \mathrm{ZrO}_{2}$. Due to the aforementioned ratio, in one mole of the solution there are actually 0.2014 moles of Sc for every 0.0092 moles of $\mathrm{Hf}$ ions, 0.0103 moles of Ce ions, 0.0140 moles of $\mathrm{Ti}$ ions, and 0.8658 moles of $\mathrm{Zr}$ ions present. Likewise there are $0.3021 \mathrm{~mol}+0.0184 \mathrm{~mol}+0.0206 \mathrm{~mol}+$ $0.0280 \mathrm{~mol}+1.7316 \mathrm{~mol}=2.1007$ moles of $\mathrm{O}$ ions.

Taking these numbers as they are, the formula for the solution would be $\mathrm{Ce}_{0.0103} \mathrm{Hf}_{0.0092} \mathrm{Sc}_{0.2014} \mathrm{Ti}_{0.0140} \mathrm{Zr}_{0.8658} \mathrm{O}_{2.1007}$. However, the formula should be of the form $\mathrm{AO}_{2}$, as this simplifies density calculations due to the fact that there are four $\mathrm{AO}_{2}$ formula units in each unit cell. To conform to this the fractions of the atoms at the A site must be normalized to 1 using the sum of all the subscripts at the $\mathrm{A}$ site, which equals 1.1007. Instead of $\mathrm{Ce}_{0.0103}$ $\mathrm{Hf}_{0.0092} \mathrm{Sc}_{0.2014} \mathrm{Ti}_{0.014} \mathrm{Zr}_{0.8658}$, the subscripts become $0.0103 / 1.1007$ $=0.0094,0.0092 / 1.1007=0.0084,0.2014 / 1.1007=0.1830$, $0.0140 / 1.1007=0.0127$, and $0.8658 / 1.1007=.7866$. The subscript of $\mathrm{O}_{2.1007}$ must also be adjusted accordingly to $2.1007 / 1.1007=1.9085$, yielding the formula of the second solution as $\mathrm{Ce}_{0.0094} \mathrm{Hf}_{0.0084} \mathrm{Sc}_{0.1830} \mathrm{Ti}_{0.0127} \mathrm{Zr}_{0.7866} \mathrm{O}_{1.9085}$ (CHSTZ) as the chemistry for the solid solution. The mass of this chemical formula is $113.939 \mathrm{amu}$. The average mass of a unit cell is thus $455.758 \mathrm{amu}$, or $7.5680 * 10^{-22}$ grams.

If the calculated lattice parameter is a $=5.09 \AA$, or $5.09 * 10^{-8}$ $\mathrm{cm}$, the theoretical density is then

$\left.\rho_{\text {CHSTZ }}=7.5680 * 10^{-22} /\left(5.09 * 10^{-8} \mathrm{~cm}\right)^{3}\right)=5.74 \mathrm{~g} / \mathrm{cm}^{3}$ 
b) $20 \mathrm{~mol} \% \mathrm{Gd}_{2} \mathrm{O}_{3}+80 \mathrm{~mol} \% \mathrm{CeO}_{2}$

The procedure for this example is very similar to that of the previous example, though somewhat simpler. One mole of the solution will contain .40 moles of $\mathrm{Gd}$ ions, .80 moles of Ce ions, and 2.20 moles of $\mathrm{O}$ ions, for a chemical formula of $\mathrm{Ce}_{0.80} \mathrm{Gd}_{0.40} \mathrm{O}_{2.20}$ which, when normalized to a ratio of 1:2, becomes $\mathrm{Ce}_{0.667} \mathrm{Gd}_{0.333} \mathrm{O}_{1.833}$ (CG).

The formula mass is then equal to $175.161 \mathrm{amu}$, which is $2.9086 * 10^{-22}$ grams. One unit cell, therefore, has an atomic mass of $1.1635^{*} 10^{-21}$ grams. The lattice parameter, as determined by $\mathrm{XRD}$, is equal to $5.424 \AA$ or $5.424 * 10^{-8} \mathrm{~cm}$. The density is then

$\rho_{\mathrm{CG}}=1.1635^{*} 10^{-21} /\left(5.424 * 10^{-8}\right)^{3}=7.29 \mathrm{~g} / \mathrm{cm}^{3}$

\section{Example of Calculation of Rock Salt}

This is the simplest of the densities to calculate. The atomic mass of $\mathrm{Ni}$ is $58.71 \mathrm{amu}$ and that of $\mathrm{O}$ is $15.999 \mathrm{amu}$, so the mass of the chemical formula is $74.709 \mathrm{amu}$. Since the mass of a unit cell is 4 times that of the chemical formula, the mass of a unit cell is equal to $298.836 \mathrm{amu}$, or $4.9623 * 10^{-22}$ grams. The lattice parameter of $\mathrm{NiO}$ is equal to $4.176 .{ }^{[4]}$ The density then is simply

$\rho_{\mathrm{NiO}}=4.9623 * 10^{-22} /\left(4.176 * 10^{-8} \mathrm{~cm}\right)^{3}=6.81 \mathrm{~g} / \mathrm{cm}^{3}$

\section{Conclusions}

The theoretical densities of important materials can be calculated if the structures of the materials are known and the lattice parameters determined using XRD analysis. In some cases, the chemical formula of the material must also be calculated. Three structures of interest in the study of SOFCs are perovskites, fluorites, and $\mathrm{NiO}$, which has the rock salt structure. The theoretical densities of the perovskites $\left(\mathrm{La}_{0.9} \mathrm{Sr}_{0.1}\right)_{0.95} \mathrm{Cr}_{0.85} \mathrm{Mg}_{0.1}$ $\mathrm{Ni}_{0.05} \mathrm{O}_{3}, \mathrm{LaMnO}_{3}$, and $\mathrm{La}_{0.6} \mathrm{Sr}_{0.4} \mathrm{Fe}_{0.8} \mathrm{Co}_{0.2} \mathrm{O}_{3}$ were calculated to be $6.40 \mathrm{~g} / \mathrm{cm}^{3}, 6.59 \mathrm{~g} / \mathrm{cm}^{3}$, and $6.36 \mathrm{~g} / \mathrm{cm}^{3}$ respectively. Those of the fluorites $\mathrm{Ce}_{0.0094} \mathrm{Hf}_{0.0084} \mathrm{Sc}_{0.1830} \mathrm{Ti}_{0.0127} \mathrm{Zr}_{0.7866} \mathrm{O}_{1.9085}$ and $\mathrm{Ce}_{0.667} \mathrm{Gd}_{0.333} \mathrm{O}_{1.833}$ were found to be $5.74 \mathrm{~g} / \mathrm{cm}^{3}$ and 7.29 $\mathrm{g} / \mathrm{cm}^{3}$, respectively. Finally, the theoretical density of $\mathrm{NiO}$ was calculated as $6.81 \mathrm{~g} / \mathrm{cm}^{3}$.

\section{Acknowledgements}

This work done at Michigan Tech under the supervision of Dr. Nina Orlovskaya in her Materials for Energy Laboratory and was funded by NSF DMR project "NSF-Europe Materials Collaboration: Self-organized Nanostructured Thin Films for Catalysis in Perovskite Related Membrane Reactors" 0502765. Rachel Rosten's summer work was funded by a Michigan Tech Summer Undergraduate Research Fellowship (SURF). Matt
Koski and Eric Koppana's summer work was funded by the Research and Engineering Apprenticeship Program of the Academy of Applied Science and the Army Research Office.

\section{References}

[1] Adler, S.B. Fuel Cells: Current Status and Future Challenges. 2005. The Bridge, 2005, 35(4), 28-32.

[2] U.S. Department of Energy. Types of Fuel Cells, Solid Oxide Fuel Cells. 04/26/06 http://www.eere.energy.gov/hydrogenandfuelcells/fuelcells/fc_types.html (accessed 7/11/06)

[3] Singhal, S.C. Solid Oxide Fuel Cells for Stationary, Mobile, and Military Applications, Solid State Ionics. 2002, 152-153, 405.

[4] International Centre for Diffraction Data ICDD Card Number 75-0269

\section{About the Authors}

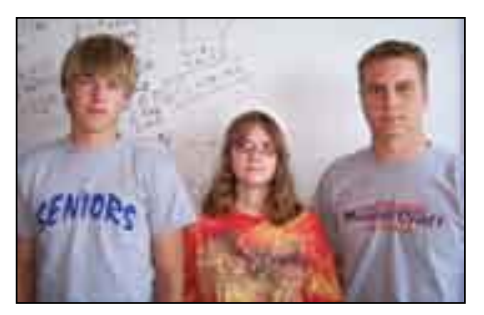

(L-R) Matt Koski, Rachel Rosten and Eric Koppana

\section{Rachel Rosten}

Rachel Rosten is a senior at Michigan Technological University pursuing a degree in Materials Science and Engineering as well as Physics with a 4.0 GPA. She is a recipient of the Provost's Award for Scholarship, the highest award for scholarship awarded to seniors at MTU. Rachel began work on the NSF project in January 2006 and has been focusing on the characterization of materials that are candidates for oxygen permeability membranes. $n$ addition she tutors in both the Math Learning Center and the Physics Learning Center, where she helps students with difficulties in undergraduate math and physics courses.

\section{Matt Koski}

Matt Koski recently graduated from L'Anse High School (L'Anse, Michigan) with a 4.0 GPA and was the valedictorian of his class. He will be a freshman at Michigan Technological University in September of 2006. Matt chose to attend Michigan Technological University because it is nationally ranked for engineering and is close to home. This summer, Matt worked in the Materials Science and Engineering Department at Michigan Tech under the Engineering Apprenticeship Program helping with research work focusing on fuel cells.

\section{Eric Koppana}

Eric Koppana is a recent graduate of Calumet High School (Michigan) with a 3.7 GPA. He will be a freshman at Michigan Technological University in the fall of 2006. His interest in engineering brought him to Michigan Tech, one of the top universities in the state. Eric was given the opportunity to work in the Materials Science and Engineering Department doing mostly fuel cell materials research in a program called the Research and Engineering Apprenticeship Program. This program is supported by the Academy of Applied Science. 